\title{
«Extranjero», nada menos que una palabra mayor
}

\author{
Enrique Santamaría
}

Universidad Nacional de Educación a Distancia. Centro asociado de Terrassa

Alcalde Perellada, 2.08222 Terrassa (Barcelona). Spain

\section{Resumen}

El artículo, partiendo de la no transparencia del atributo aextranjero" y tomando como pre-texto a Simmel y Durkheim, analiza la posición social que el «extranjeron ocupa en el espacio social e imaginario de la sociedad de la que forma parte $y$, así mismo, el papel que determinadas agencias y agentes sociales juegan en la producción y reproducción de aquella figura social.

Palabras clave: extranjero, diversidad humana, agentes sociales, (re)producción social.

\section{Abstract. "Foreigner"}

The article, pointing out the non-transpatency of the attribute "foreignen and raking as pretext Simmel and Durkheim, analyses the social position the "foreigner" occupies in the social and imaginary space within the society of which it forms part, and also the role played by certain social agencies and agents in the production and reproduction of this social figure.

Key words: foreigner, human diversity, social agents, social (re)production.

¿Habrá alguna idea que merezca no ser pensada de nuevo?

(Elias Canetti)

El sociblogo que, como cualquier otro sujeto, se encuentra inmerso en un mundo que ha sido ya nombrado, y por lo tanto demarcado y configurado, tiene por tarea reconstruir, desentrañar, aquellos procesos sociales que atraviesan y constituyen este mundo social. Es por ello que toda práctica sociológica de elucidación, de escrutinio, de un fenómeno sacial requiere una serie de operaciones, consecutivas y jerarquizadas, de carácter epistemológico, metodológico y técnico, que se enfrenten en primer lugar a este hecho. Antes de ponerse a comprobar las hipótesis y las intuiciones que guían la investigación, al soció- 
logo le resulta imprescindible operar una ruptura con las representaciones que capturan los fenómenos sociales con el fin de construir el campo social que define al sujeto/objeto de estudio y de evitar que se le deslice subrepticiamente toda la violencia simbólica que las cosas - a través de su nominación- llevan adherida y de la que son vehículo de transmisión.

Es esta lógica la que nos ha llevado a abordar en otros lugares las (re)presentaciones sociales en la prensa diaria y en las instancias socio-reparadoras (Santamaría, 1993a, 1993b), como lugares estratégicos de (re)producción de las mismas, y la que nos Ileva en esta ocasión a sumergirnos en las profundas y normalmente refrescantes y nutricias aguas de la teoría sociológica. Esta densificación preliminar y constante de la mirada sociológica es un paso necesario, pues, para no caer en los espejismos de conocimiento espontáneo de los que participa ese empirismo y pragmatismo socioasistencial que predomina en los "estudios" -en su mayor parte registros sociográficos que no análisis sociologicos - que en la actualidad proliferan sobre el tema que nos ocupa.

Estas páginas, que se centrarán en la exposición de dos fragmentos de Simmel y Durkheim, no tienen como intención realizar un análisis pormenorizado y exhaustivo de estos autores, sino que, apropiándonos de la propuesta proustiana de considerar un libro como unas gafas, cuya utilidad o inutilidad radica en si consigue hacernos ver mejor, pretenden hacerlos servir como una lente que nos permita ajustar de una forma más potente la construcción de nuestro objeto de investigación y de los artefactos técricos que utilizaremos para penetrarlo. De otro modo, a lo largo de estas páginas, haremos uso de los textos, pequeños pero sugerentes, de estos autores como pre-texto para profundizar en nuestro viaje y complejizar nuestra mirada sobre esa hipóstasis del "extranjero" que es la así llamada «inmigración no comunitaria".

Si bien todas y cada una de las sociedades han producido, inventado, constituido, sus propios uextranjeros», es necesario señalar para el caso de nuestra sociedad que esta figura de la alteridad está marcada por la configuración hegemónica de las sociedades en estados-nación, o lo que es lo mismo, por la preponderancia de la nacionalización y estatalización de los fenómenos sociales. En este sentido, si bien cada estado es el que determina, a través de su aparato sociojurídico, a través de esos agentes y agencias que tienen como función deffnir y regular los límites de las personas y actividades, quienes son (y qué no son) sus miembros, sus "nacionales" —es más, sus ciudadanos-, sin embargo, transversal y subyacentemente a esta extranjería jurídica hay una extranjería social que se formaliza, se condensa, coagula, en el plano de la vida cotidiana y en los espacios relativos a ésta.

Es en esta dimensión en la que se sitúa la famosa digresión de Simmel sobre esa figura social que es el uextranjero". En el capítulo dedicado al espacio y la sociedad de su Sociología este autor define la posición singular que ocupa el "extranjero" en la sociedad de la que forma parte. El uextranjero" es un "tipo social» que, en el marco de esa trama de relaciones sociales que convencionalmente denominamos sociedad, no se caracteriza exclusivamente por su exterioridad, no es el que está fuera del oasis, el que habita ese otro universo que es 
el desierto, sino que, por el contrario, viene definido por la aproximación e implantación de esta exterioridad en un espacio geográfico y social concreto. El "extranjero" de Simmel no es ni el nómada (en cuanto signiffca la no vinculación a un punto del espacio, la movilidad absoluta) ni el sedentario (en cuanto significa el asentamiento social, la inmovilidad), es una forma transversal a ambos: para Simmel, el "extranjero" en una comunidad "no es el que viene hoy y se va mañana; es, por decirlo así, el emigrante en potencia, que aunque se haya detenido, no se ha asentado completamente».

El «extranjero", por consiguiente, no remite a lo que hoy denominamos, utilizando palabras de Affergan, la "alteridad lejana" (1987, 27), a esa alteridad que es imaginada antes que percibida, pues ésta es inexistente para los miembros de la comunidad al estar más allá de la proximidad y de la lejanía que define sus contornos. Más bien el "extranjero" de Simmel es esa alteridad que se ha "fijado", implantado, provisional aunque de hecho duraderamente, en un territorio. Es esa figura lejana y próxima a la vez, que exige una situación de interacción y que se configura, asume, una forma social concreta en ese entramado territorial que denominamos ciudad. Dicho de otro modo, el extranjero no es el bárbaro, el tártaro, el bereber, todos ellos habitantes ajenos a la ciudad y por eilo mismo a la humanidad, sino que es el meteco, el extraño (ya sea bajo la forma de "forastero", "inmigrante", "desconocido", "advenedizon, etc.), es esa presencia provisional y duradera a la vez (Sayad, 1991) que se define por no pertenecer a ese espacio social desde siempre y por incorporar cualidades que presuntamente no proceden ni pueden proceder de él.

$\mathrm{El}$ «extranjeron es un elemento del grupo mismo que, como los pobres y las diversas clases de "enemigos interiores", si bien, por una parte, ocupa una posición de miembro, por otra, está como fuera o enfrente. EI "extranjero", como venimos diciendo, ya no es el salvaje, o lo que es lo mismo, el indigena de un territorio ajeno, lejano o ignoto, sino el intruso, que con sus diferentes expresiones sociales habita en esa tensión del afuera y enfrente pero dentro que constituye el carácter formal de la posición de "extranjero".

Simmel, a lo largo de esta profunda y sucinta digresión, en la que define la posición social del "extranjero", analiza además las diferentes funciones sociales y económicas que aquél cumple o le son impuestas, así como la compleja y ambivalente posición que ocupa en el imaginario social. Con respecto a las primeras, Simmel señala la dedicación del "extranjero" a las actividades periféricas e incluso marginales del sistema socioeconómico; actividades que si bien ayer, en una sociedad agraria y autárquica, confluían en el comercio (de mercaderías y/o de dinero) hoy en día estarían representadas por la venta ambulante, las tareas agrícolas, el trabajo sumergido y negro,... y todas aquellas actividades económicas provisionales e inciertas que el «extranjeron desempeña y que al fin y al cabo le confieren este carácter específico de la movilidad y de la precariedad en el cual se manifiesta aquella síntesis de lę̧anía y proximidad que lo configura.

Esros desempeños, que no se reducen a su funcionalidad económica, connotan al "extranjero" como atopos, como una figura social desprovista de lugar apropiado en el espacio social y de lugar asignado en las clasificaciones socia- 
les. "Como Sócrates —observa Bourdieu (1991: 9) - el inmigrante es atopos, sin lugar, desplazado e inclasificable. [...] Ni ciudadano ni extranjero, ni verdaderamente del lado de lo Mismo, ni totalmente del lado de lo Otro, el "inmigrante" se sirúa en ese lugar "bastardo" del cual habla también Platón, la frontera del ser y del no ser social." El "extranjeron es, para decirlo de otro modo, el habitante de los márgenes sociales, de las fronteras -en definitiva, de su continuo trasiego.

Esta constitución del "extranjero" como atopos adopta, según Simmel, una constelación de expresiones entre las que sobresale la configuración del extranjero como una figura social objetiva, como una figura social desinteresada -que no sin intereses. Para Simmel, la figura del "extranjero" no sólo no se reduce a una figura amenazante y totalmente ajena al grupo, sino que comporta toda una serie de expresiones distintas a esta configuración de la extranjería. En este sentido, Simmel destaca la participación del uextranjero" como testigo imparcial y desinteresado, como confidente perfecto, e incluso como encarnación del individuo libre,... ya que, como consecuencia de su atopía, de ser una síntesis de lejanía y proximidad, se trata de una figura social que no está constreñida por intereses de grupo y de fracción, que no está ligada por ninguna consideración que pudiera constituir un prejuicio para la percepción, la comprensión y estimación justa de hechos y decires. Pero estas expresiones de la posición de «extranjero", que lo convierten en metáfora misma de la humanidad (de la condición humana, que diría Hannah Arendt), en determinadas circunstancias corren el riesgo y de hecho son interpretadas como una amenaza a la cohesión del grupo; el uextranjero" es considerado entonces como agente enemigo infiltrado y disolvente de la propia comunidad y al cual le son atribuidos los problemas de la misma.

Tras describir algunas de las manifestaciones, positivas y negativas, que puede adoptar la figura del "extranjero", Simmel pasa a analizar el tipo de relación que la comunidad mantiene con él, que es predominantemente de carácter abstracto, universalista. Frente a una interrelación entre los miembros de un grupo que se constituye de manera preponderante a partir de los rasgos diferenciales particularistas, en la relación "con el extranjero - observa Simmel-, sólo se tienen de común ciertas cualidades de orden general». El "extranjero" no es considerado, por tanto, como un individuo particular con el que se mantienen relaciones en función de esta particularidad, sino que es la encarnación, la corporalización, de una categoría social que lo engloba y define más allá de sí mismo: es un "moro", un "gabacho", un "inmigrante", un "girano", un "alemán", etc.

Esta "relación abstracta", que en mayor o menor grado caracteriza a todas las relaciones interpersonales, no es el resultado de la existencia de características compartidas y diferenciales entre los individuos, sino que tiene su origen, y sobre todo en el caso del "extranjero", en el carácter genérico, vago, en que los miembros sienten esa comunidad. Simmel nos recuerda que la acción de lo común se debilita en proporción a la amplitud del círculo en el que se contenga de un modo general esa comunidad: «a medida que los elementos comu- 
nes tienen un carácter más general, el calor de la relación creada por ellos se convierte en frialdad y deja paso al sentimiento de que esta relación es casual". Es por ello que para Simmel esta relación abstracta de la comunidad con el "extranjero" procede, lo que no es en absoluto paradójico, "de que la relación se basa en la igualdad general humana"; en ese bumanismo que, como denuncia Jesús Ibáñez (1993): "fetichiza una cierta idea de hombre, una cierta idea del Hombre». Esta fundamentación universalista tiene como consecuencia que entre lo particular y lo general se produzca una tensión que no puede resolverse más que en la negación de la particularidad, uporque la conciencia de no tener de común más que lo general — nos dice Simmel- hace que se acentúe especialmente lo no común. De ahí que en el caso de los extranjeros por nacionalidad, ciudad o raza, to que se ve en ellos no es lo individual, sino la procedencia extranjera, que es o podría ser común a muchos extranjeros. Por eso a los extranjeros no se les siente propiamente como individuos, sino como extranjeros de un tipo determinado. Frente a ellos, el elemento de alejamiento no es menos general que el de la proximidad."

En el esclarecimiento de este fenómeno al que alude Simmel resulta útil la problematización que, desde otra perspectiva y con otro objeto, Durkheim realiza sobre la actitud de los franceses con respecto a la diversidad humana. Este, en los dos últimos capítulos-conclusión de su Historia de la educación y de las doctrinas pedagógicas. La evolución pedagógica en Francia, en los que se pregunra sobre los modos de enseñar las cosas humanas y de la naturaleza, observa que la sociedad francesa está afectada por una progresiva escotomización que la ha ido dejando totalmente insensible a la percepción y reconocimiento de la diversidad y complejidad humanas.

Esta discapacidad, de carácrer pandémico, que vela y silencia de forma sistemática todo aquello que hace de los individuos individuos concretos, enmarcados en un tiempo y espacio determinados, resaltando todo lo que de impersonal y general tienen, no es en absoluto innata o natural, nos dice Durkheim. No está enraizada en una supuesta constitución congénita o racial de los franceses, sino que es una actitud adquirida, una actitud (re)producida, creada, mediante un determinado tipo de transmisión cultural que, desde la segunda mitad del siglo XVI, predomina en la sociedad francesa.

Este tipo de transmisión dominante, que Durkheim denomina «educación humanistan, se caracteriza por apropiarse del irreductiblemente complejo y diverso mundo humano y (re)presentarlo, transmitirlo, como pura apariencia, como mero y superficial producto de la ilusión de los sentidos. Esta (re)presentación de lo diverso y lo complejo como algo simple y accesorio a lo que verdaderamente es esencial tiene como primera consecuencia hacer a los individuos incapaces de pensar otra cosa distinta de lo abstracto, lo general y lo simple. En este sentido, la "educación humanista" produce individuos afectados, diagnostica Durkheim, de "una especie de ceguera intelectual [...] que oblitera el sentido de lo diverso, de lo complejo [...] [haciendo ver] en esos caracteres múltiples y complejos que forman la fisonomía particular de cada uno de nosotros, que hacen que el hombre de un país y de una condición no 
sea el hombre de otra condición y de otro país, detalles accesorios que podían olvidarse sin inconveniente, de los que convenía incluso hacer abstracción para liegar a lo que tiene de esencial, es decir, de invariable y universal.»

Pero para Durkheim este fenómeno no afecta sólo a la (re)presentación de la diversidad y complejidad humana en la institución escolar, sino que tiene su correlato y continuidad a nivel sociopolítico en el, por él, denominado "cosmopolitismo constitucional» francés. Este, encarnado en la declaración de los derechos del hombre, no es, como señala en uno de sus primeros escritos, Les principes de 1789 et la sociologie, sino "el resultado de todo un proceso inconsciente que en tanto que hechos sociales expresan l'état d'âme de una sociedad" (Mauviel, 1989). Un état d'áme que no es la expresión de una presunta naturaleza nacional, del presunto espíritu de un pueblo, sino que es producto de unos determinados procesos sociohistóricos, de unas determinadas prácticas y conflictos sociales.

El autor considera que cuando una sociedad, sus agentes y agencias, se basa en una representación social del hombre desitgado de todas las contingencias que lo engranan social y culturalmente haciendo de el un ser social, y que no subraya sino lo que de más general y abstracto tiene, sólo puede adherirse a un ideal válido para todo el género humano, sólo puede fundamentarse en un individualismo abstracto, en una concepción atomística de la sociedad y en el desprecio por la historia. En definitiva, la "educación humanística", que participa profusamente de esta caracterización, reposa sobre el principio de una naturaleza humana, fija e invariable, esencial, con respecto a la cual aquélla no tendría otra misión que desarrollarla, liberarla, en cada uno de los individuos que componen la sociedad. Esto conlleva como corolario la (re)presentación del hombre como hombre natural, universal y transhistórico, que no sería, en cada uno de los diversos contextos sociohistóricos, el producto de la dinámica social. El hombre no se haría, no se individualizaría en sociedad, sino que por el contrario es esta última la que lo malformaría y constriñería, no dejándole desarrollar todas sus porencialidades naturales. Es esto último lo que constituiría la fundamental tarea de la escuela y los docentes: ayudar, animar, asistir al desarrollo, a la extracción, de las potencialidades biopsicosociales consustanciales at hombre y que la sociedad no hace sino constreñir y mutilar. Lo social queda así reducido a desempentar un papel negativo e incluso insignificante: como dice Lerena, a convertirse en "sinónimo de lo artificial, lo externo, lo que disturba; aigo con lo que hay que contar, pero que es necesario mantener afuera, porque es el accidente y no la sustancia, la cáscara y no el meollo, ni de lo que el hombre es ni de lo que es la educación" $(1985,55)$.

La "humanidad" dejaría, desde esta perspectiva, de ser un producto social e histórico; aquélla, con su complejidad y diversidad, no sería el resultado de diferentes procesos y dinámicas sociohistóricas y, por consiguienre, no estaría tampoco llamada a transformarse sin fin y de una forma radical en el futuro. "Ahora bien — nos señala Durkheim - no existe afirmación en más flagrante contradicción con las enseñanzas de la historia. Lejos de ser invariable, la humanidad se hace, se deshace, se rehace sin cesar; lejos de ser una, es infinitamen- 
te diversa, tanto en el tiempo como en el espacion. En definitiva, esta inagotable diversidad, que no se reduce a meras manifestaciones externas y epifenoménicas de un núcleo simple y esencial, no hace sino expresar la variedad sin fin que adopta la existencia colectiva, por lo que una transmisión educativa que la pretenda (re)conocer debe centrarse, para Durkheim, en la explicitación de las condiciones necesarias para la génesis y el desarrollo de la misma. En esta tarea, de comprensión de lo que el hombre tiene de "fuerza infinitamente flexible y proteiformen, juega un papel fundamental la sociologia, esa forma de mirar la realidad que se llama imaginación sociológica, y que para Durkheim tiene un importante papel «moral» —ético, diríamos hoy.

Llegados a este punto no nos queda sino recapitular, dando por concluida esta exposición a los textos de dos "clásicos" de la sociologia que ha tenido como finalidad densificar nuestra mirada, armarla mejor para la comprensión de un fenómeno social que, como tal, no puede ser sino complejo. A través de esta exposición nuestra mirada se ha impresionado de nuevas preguntas, de otras formas de interrogación: ¿cuál es la posición del "extranjeron en el espacio social y simbólico?, ¿cuáles son las manifestaciones que adopta esta figura en la sociedad? y ¿en el imaginario social?, ¿qué tipo de relación mantiene la comunidad con esta figura social?, ¿cómo se crea o produce socialmente este tipo de relación?, ¿qué agencias y agentes intervienen?, ¿a través de qué prácticas?, etc. Otros interrogantes que se han traducido en una provisional y cauta aproximación a la significación social del "extranjero" y que han tenido como primordial efecto problematizar la reflexión sobre ese fenómeno en cuyo (re) conocimiento estamos empeñados. En resumidas cuentas, han hecho posible subvertir por uno de sus principales nódulos, por una de sus palabras mayores, esa red de palabras que poco a poco va capturando y confinando al fenómeno migratorio, a sus protagonistas, en la violenta y sorda eficacia de lo impensado: de lo evidente por sí mismo.

\section{Bibliografía}

AfFERGAN, Francis (1987). Exotisme et altérité. París: PUF (Sociologie d'aujourd'hui). BOURDIEU, Pierre (1991). "Preface». En SAYAD, Abdelmalek. L'immigration. Ou les paradoxes de l'altérité. París: Editions Universitaires, p. 5-9.

DURKHEIM, Emile (1982). Historia de la educación y de las doctrinas pedagógicas. La evolución pedagógica en Francia. Madrid: La Piqueta (Genealogia del poder).

IBÁNEZ, Jesús (1993). "Los haceres y decires europeos". Archipiélago. Cuadernos de critica de la cultura, núm. 14, p. 103-105. Barcelona.

LERENA, Carios (1985). Materiales de Sociologia de la educación y de la cultura. Madrid: Zero (Por un nuevo saber).

MaVIEL, Maurice (1989). "La tevolution française er les étrangers. Persistance d"une conscience collective: de l'étranger de 1789 a l'immigré de 1989". Cahiers de Sociologie Economique et Culturelle (Ethnopsychologie), núm. 11, p. 9-35. París.

RAPHAEL, Freddy (1986). "L'etranger" de Georg Simmel". En WaTIER, Patrick (Dir.). Georg Simmel. La sociologie et l'expérience du monde modeme. París: Méridiens Klincksieck, p. 257-278. 
SANTAMARfa, Entique (1993a). "(Re)presentación de una presencia. La "inmigración" en y a través de la prensa diaria". Archipiélago. Cuadernos de Critica de la Cultura, núm. 12, p. 65-72. Batcelona.

SANTAMARfa, Enrique (1993b). "El "bloqueo del Estrecho" en la prensa: zuna metáfora de la crisis?m. En ProvanSAL, Danielle (Coord.). Migraciones, Segregacion y Racismo. Tenerife: Actas del VI Congreso de Antropologia, p. 29-37.

SAYAD, Abdelmalek (1991). Limmigration. Ou les paradoxes de l'alterité. París: Edirions Universitaires.

SIMMEL, Georg (1977). „Digresión sobre el extranjero». Sociología. Estudio sobre las formas de socialización. Madrid: Revista de Occidente, vol. II, $2^{\star}$ ed., p. 716-722. 